\author{
Igor BARÉNYI ${ }^{1}$ \\ Maroš ECKERT ${ }^{2}$ \\ Jozef MAJERÍK ${ }^{3}$ \\ Ján BEZECNÝ 4
}

\title{
AFM AND NANOINDENTATION STUDY OF SELECTED ALUMINIUM ALLOYS
}

\begin{abstract}
The structure of EN AW 6082 aluminium alloy is investigated in this paper. Atom force microscopy (AFM) is used to identify present phases and their morphology. AFM enabled to observe even the precipitates, their size and distribution. In the next step, some structure constituent described by AFM were evaluated by the nanoindentation process to determine their local mechanical properties, such as nanohardness and reduced modulus.
\end{abstract}

Keywords: aluminium alloy, structure constituent, nanoindentation, precipitates

\section{Introduction}

Aluminium alloy of EN AW 6082 (AlSi1MgMn) is a medium-strength alloy with excellent corrosion resistance. Within the alloys series $6 \mathrm{xxx}$ has the highest strength and is also known as a structural alloy that is used for construction parts of various machines and equipment, also in the automotive industry. The alloy has excellent mechanical properties, wear resistance and low density. The alloy, in the form of plates, especially designed for machining. As a relatively new alloy, the older EN AW 6061 has been replaced in many applications for its higher strength.

Adding a large amount of manganese affects the grain size, which results in an increase in alloy strength. It is rather difficult to produce a thin wall or a complicated extruded shape from the EN AW 6082 alloy, and the finished surface is not as smooth as that of similar 6xxx series alloys. In the T6 and T651 heat treatment, the EN AW 6082 alloy is well machined and forms continuous chips.

\footnotetext{
${ }^{1}$ Corresponding author/autor do korespondencji: Igor Barényi, Alexander Dubcek University of Trencin, Studentska 2, Trencin, Slovakia, e-mail: igor.barenyi@tnuni.sk

2 Maroš Eckert, Alexander Dubcek University of Trencin, e-mail: maros.eckert@tnuni.sk

3 Jozef Majerík, Alexander Dubcek University of Trencin, e-mail: jozef.majerik@tnuni.sk

4 Ján Bezecný, Alexander Dubcek University of Trencin, e-mail: jan.bezecny@tnuni.sk
} 
The EN AW 6082 alloy is mainly alloyed with magnesium and silicon. At higher magnesium content, they tend to increase the strength of the hardened alloy by forming fine $\mathrm{Mg}_{2} \mathrm{Si}$ precipitates. Silicon improves mechanical properties by a changing the shape of grains. Apart from major alloying elements, chromium and manganese are added to the alloy, forming dispersion particles. These are larger than other precipitates and can act as nucleation points for precipitates and concurrently have good thermal stability.

In aluminium alloys $\mathrm{Fe}$ is the most common impurity, which is manifested by formation of the intermetallic phases Al-Fe, Al-Fe-Si and Al-Fe-Mn-Si, depending on the type of alloy. The solubility of $\mathrm{Fe}$ in $\mathrm{Al}$ is very low, therefore, in commercial aluminium alloys, primary $\mathrm{Fe}$ particles are always present. In the 6xxx alloy series containing $\mathrm{Fe}, \mathrm{Si}$ and $\mathrm{Mn}$, particles of $\mathrm{Al}_{5} \mathrm{FeSi}, \mathrm{Al}_{12}\left(\mathrm{Fe}_{\mathrm{x}} \mathrm{Mn}_{(1-\mathrm{x})}\right)_{3}$ $\mathrm{Si}$ and $\mathrm{Mg}_{2} \mathrm{Si}$ are formed during solidification $[1,2]$. Cast microstructures are dendritic; AlFeSi phases and coarse particles of $\mathrm{Mg}_{2} \mathrm{Si}$ are preferably secreted in the interdendritic areas.

Improvement of the mechanical properties of this type of aluminium alloy is possible by forming and also by means of heat treatment consisting of solution treatment, quenching in water, and natural or artificial ageing. From unstable saturated solid solution (SSSS), the alloy becomes almost stable during aging. The process precipitates formation should be according to the following scheme: $\mathrm{SSSS} \rightarrow$ GP zone $\rightarrow$ pre- $\beta^{\prime \prime}\left((\mathrm{Al}+\mathrm{Mg})_{5} \mathrm{Si}_{6}\right) \rightarrow \beta^{\prime \prime}\left(\mathrm{Mg}_{5} \mathrm{Si}_{6}, \mathrm{Al}_{3} \mathrm{MgSi}_{6}\right) \rightarrow$ $\beta^{\prime}\left(\mathrm{Mg}_{9} \mathrm{Si}_{5}\right), \mathrm{B}^{\prime}, \mathrm{U} 1\left(\mathrm{MgAl}_{2} \mathrm{Si}_{2}, \mathrm{MgAl}_{4} \mathrm{Si}_{5}\right), \mathrm{U} 2\left(\mathrm{Mg}_{2} \mathrm{Al}_{4} \mathrm{Si}_{5}, \mathrm{MgAlSi}\right) \rightarrow \beta\left(\mathrm{Mg}_{2} \mathrm{Si}\right)$. GP zones representing meta-stabile phases (or precipitates), are crystallographically coherent with the matrix and their fine dispersion improving the mechanical properties of the alloy. The coherent meta-stable phase $\mathrm{B}^{\prime}, \mathrm{U} 1$ and $\mathrm{U} 2$ coexist with the transformation of $\beta[3,4]$. An increase it the ratio of $\mathrm{Mg}: \mathrm{Si}$ also increases the strength of the alloy [5]. Copper addition to the alloy creates a precursor $\mathrm{Q}^{\prime}$ phase $\left(\mathrm{Al}_{4} \mathrm{CuMg}_{6} \mathrm{Si}_{6}\right)$ and stable Q phase $\left(\mathrm{Al}_{4} \mathrm{Cu}_{2} \mathrm{Mg}_{8} \mathrm{Si}_{7}\right)$. Due to the low diffusion of $\mathrm{Cu}$ into $\alpha-\mathrm{Al}$ and subsequent coarsening of the $\mathrm{Q}^{\prime}$ phase the alloys are thermally stable [6-8]. On the other hand, alloys with copper have less corrosion resistance.

\section{Material and methods}

As an experimental material, EN AW 6082-T651 aluminum alloy was used in this paper. The heat treatment was set to T651 - solution heat treatment, stress relief by stretching and then artificially ageing. The examined samples were prepared in the longitudinal and transverse directions. Due to the fact that the objective of the article was to examine the precipitates, most attention was paid to examination of the sample prepared in the transverse direction. Basic chemical composition of the experimental material measured by Spectrolab Jr CCD spectral analyser is in Tab. 1. Microstructure of the experimental sample observed by using optic metallography is in Fig. 1. White base matrix of the solid solution $\alpha$ ( $\mathrm{Si}$ in 
$\mathrm{Al}$ ) with regularly distributed $\mathrm{Mg}_{2} \mathrm{Si}$ dark particles are visible only at the $1000 \mathrm{x}$ magnificence. Morphology or presence of other possible phases is one of the goals in the presented experiments.

Table 1. Chemical composition of EN AW 6082-T651 (wt.\%)

\begin{tabular}{|l|c|c|c|c|c|c|c|c|c|}
\hline Element & $\mathrm{Si}$ & $\mathrm{Mg}$ & $\mathrm{Mn}$ & $\mathrm{Fe}$ & $\mathrm{Zn}$ & $\mathrm{Cu}$ & $\mathrm{Ti}$ & $\mathrm{Cr}$ & $\mathrm{Al}$ \\
\hline wt.\% & 0.947 & 0.619 & 0.551 & 0.495 & 0.119 & 0.078 & 0.025 & 0.029 & 97.02 \\
\hline
\end{tabular}

Fig. 1. Mictrostructure of EN AW 6082-T651 in transverse direction

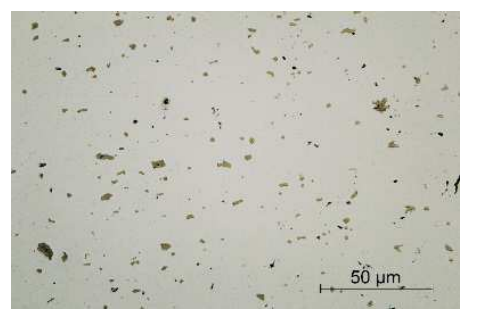

AFM (Atomic Force Microscopy) is an uncommonly used method for investigating the micro and nano structures of metallic materials. The principle of this microscope is to scan the sample surface with a very small tip, which has a tipradius of only a few nanometers. Thanks to this, it is possible to obtain a surface image with depth information; the height of artifacts on the surface, also known as topography of surface. With the development of AFM, other ways of scanning the surface have come, together with the possibility of examining other surface properties of samples, such as electrostatic, thermal or magnetic ones. In the material sciences, the most interesting modes are those that measure Young module, indentation, hardness or dissipation. The Oxford Instruments MFP-3D Infinity AFM microscope on which measurements have been done, enables exploring material properties using the AM-FM Viscoelastic Mapping Mode.

The AM-FM mode can register nanomechanical properties of materials across a wide range of Young modules (from less than $1 \mathrm{MPa}$ to hundreds of GPa), from biomaterials to metals and ceramics. The AM-FM mode obtains results by working at two cantilever resonances simultaneously (Fig. 2). As the name suggests, the first resonance is used for tapping mode imaging, also known as amplitude modulation (AM), while the resonance mode works with frequency modulation (FM). In the case of resonances, the cantilever frequency and phase respond sensitively to changes in sample properties. 


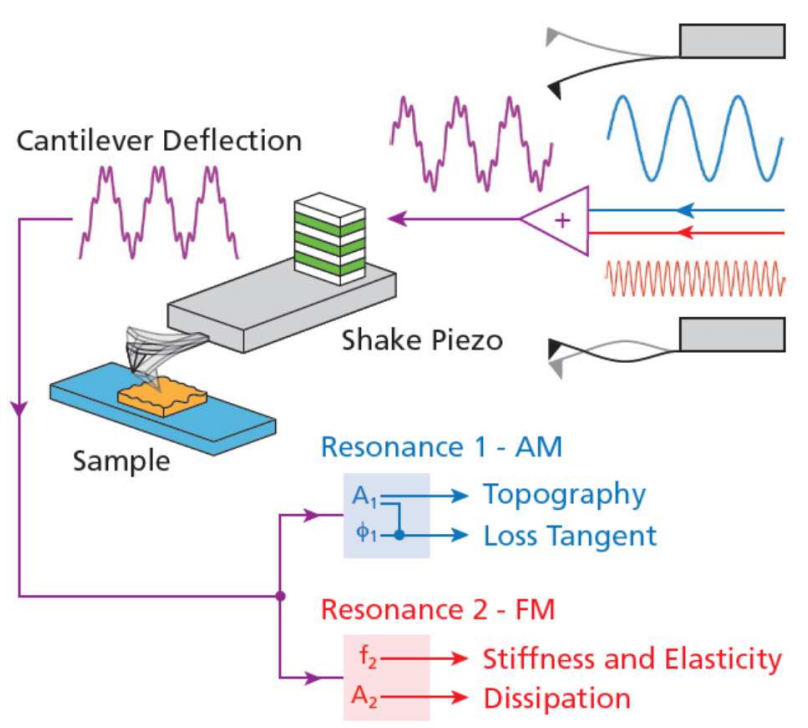

Fig. 2. Schematic of the operation in AM-FM mode

The AM-FM mode has its roots in multi-frequency and bimodal AFM microscope modes. Signals from two oscillators are summarized and sent to a piezo element that operates in two selected modes at the same time. The first and second bending resonance are most often used, but a third or even higher resonances can be used. The cantilever reaction is analyzed in two ways. The lower cantilever resonance operates in AM mode. The amplitude and phase at a fixed frequency are measured by a lock-in amplifier. The AFM also uses the amplitude for feedback control, adjusting the cantilever's vertical position to maintain the amplitude at the setpoint value. The second lock-in measures the phase operates in the FM mode. An automatic gain control circuit monitors the phase and adjusts the drive frequency to maintain the phase at $90^{\circ}$. The output drive voltage signal contains information on viscous or dissipative forces. The output response frequency describes the elastic tip-sample interactions. Basically, higher frequency means greater stiffness or modulus. A parameter describing mechanical properties of the surface is also the indentation. Indentation represents deformation of the surface when the tip is tapping on the surface. Larger indentation or deformation means less surface hardness. It is also possible to get high surface resolution based on the mechanical surface properties in the dissipated channel. This channel measures the amount of energy dissipated from the tapping tip onto the sample. All of these channels often provide much better resolution and provide a better view of the sample surface than just ordinary height channel.

Quasistatic nanoindentation tests involve pushing a diamond tipped indenter head into a material under either load or displacement control. The displacement $(h)$ is monitored as a function of the load $(P)$ throughout the load-unload cycle, 
where the resulting relation $P-h$ is called the nanoindentation curve. However, elastic - plastic contact occurs in real materials. There were both plastic and elastic deformations during the indentation test on the examined material surface. Once the forces are no longer applied, the elastic part of deformation is recovered, where the plastic part remains in a form of indent (impress) on the material surface [9]. The plastic part of deformation is typically used to determine Young's Modulus, while the elastic-plastic part both with indented surface is used to evaluate the hardness. The area bounded by both loading and unloading curves is equivalent to dissipation energy. Hardness $(H)$ is defined as the contact pressure under the indenter:

$$
H=\frac{P}{A_{c}}
$$

where $P$ is the load and $A_{c}$ is the projected contact area calculated at a depth of indentation $h$. The initial slope (S) of the unloading curve can be related to the elastic modulus of the material using the equation:

$$
S=\frac{d P}{d h}=\frac{2 E_{r} \sqrt{A_{c}}}{\sqrt{\pi}}
$$

where: $S$ is the initial slope of the unloading curve or contact stiffness, $P$ is the applied load and $E_{r}$ is the reduced modulus.

As the measured displacement in a nanoindentation experiment is a combination of the displacement of the indenter tip as well as the specimen, the specimen modulus $\left(E_{s}\right)$ can be related to the reduced modulus $\left(E_{r}\right)$ using equation 3 provided the indenter modulus $\left(E_{i}\right)$ is known and the Poisson's ratios of the specimen and indenter ( $\underline{v}_{s}$ and $v_{i}$ respectively) are known or can be estimated:

$$
\frac{1}{E_{r}}=\frac{1-v_{S}^{2}}{E_{S}}+\frac{1-v_{i}^{2}}{E_{i}}
$$

When determining material properties such as hardness and elastic modulus, a three-sided diamond pyramid (the angle between centre axis and faces $\alpha=62.25^{\circ}$ ) indenter known as the Berkovich indentation tip is commonly used. According to some authors $[10,11]$ the diamond indenter behaves rigidly and equation 3 can be reduced to equation 4 by assuming $E_{i}$. When determining material properties such as hardness and elastic modulus a three-sided diamond pyramid indenter known as Berkovich indentation tip (can be seen in Fig. 4) is commonly used:

$$
\frac{1}{E_{r}}=\frac{1-v_{S}^{2}}{E_{S}}
$$




\section{Results and discussion}

AF-FM Viscoelastic mode was used to show nanostructures and precipitates in the EN AW 6082 aluminum alloy, in which it is possible to differentiate the particles on the sample surface on the basis of their different mechanical properties. From the measurement point of view, it is preferable to measure relative frequency shifts as the absolute amplitude or height shift measurement. Relative measurements reduce common sources of systematic errors, while smaller bandwidths in frequency selective methods also mean less noise. Both effects lead to greater accuracy and better resolution [12].

AFM images were created with AC 160TS cantilever with a resonance frequency of $200-300 \mathrm{kHz}$. For images with a large size $(50-90 \mu \mathrm{m})$ and relatively small magnification, it was best to use the output from the frequency channel that provided the best sharpness of contrast. Figure 3 shows the $A l_{x}(\mathrm{Fe}, \mathrm{Mn})_{\mathrm{y}} \mathrm{Si}_{\mathrm{z}}$ phase from the frequency channel. This phase in the height channel cannot be identified jlike optical microscopy without surface etching. The picture also shows that the phase has a greater stiffness than the surrounding $\alpha$ (Al-Si) matrix. Figure 4 shows the output from the channels obtained in the AM-FM mode with relatively large magnification. As it can be seen from in the images, the height channel provides a non-sharpened image of particles of different sizes. Conversely, other channels, such as dissipation, frequency and indentation provide sharp particle imaging as well as very fine precipitates of only a few dozen nanometers.

A similar magnification and resolution would only be possible with TEM microscopy (Transmission Electron Microscopy), but the preparation of the sample is much more complex than for AFM, as a standard polished metallographic sample is sufficient. In Fig. 3b-d it is possible to see larger particles of several hundred nanometres, which may be intermetallic particles and larger precipitates. Furthermore, very dispersive spherical precipitates can be seen there. These particles should represent GP zones or other intermediate precipitations.

The size and distribution of very small precipitates was evaluated using a grain and particle evaluation program on AFM images Gwyddion. In Fig. 5 one can see indicated red precipitates from which the particle size distribution was constructed. The particle size was evaluated using an equivalent radius of circular particle having the same surface area as a real particle. The particles were measured and selected from a surface of $1 \mathrm{x} 1 \mu \mathrm{m}^{2}$.

The size of very fine precipitates expressed in the form of the equivalent radius is shown graphically in Fig. 6. It can be seen that most precipitates (up to $18 \%$ ) are about $2.5 \mathrm{~nm}$ (diameter $5 \mathrm{~nm}$ ). With the increasing size of precipitates, their frequency of occurrence decreases. Table 2 shows statistical data of the size of precipitates, the average equivalent precipitate radius is $8.255 \mathrm{~nm}$ and the median, i.e. the value about/below which $50 \%$ of all precipitates are, amounts $5.42 \mathrm{~nm}$. 
a)

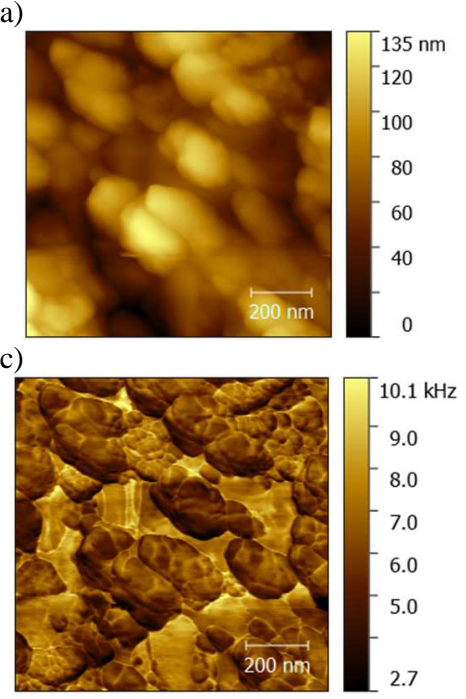

b)

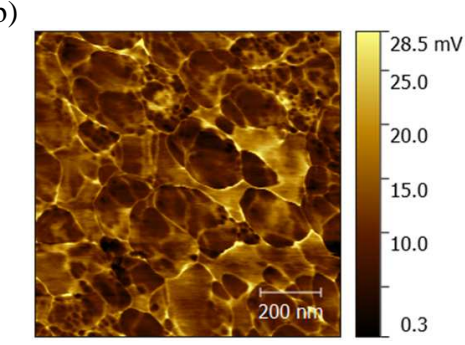

d)

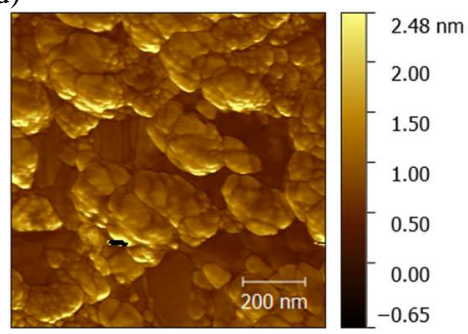

Fig. 3. AM-FM mode images of: a) Height channel, b) Dissipation channel, c) Frequency channel, d) Indentation channel

Fig. 4. Frequency channel image of grain

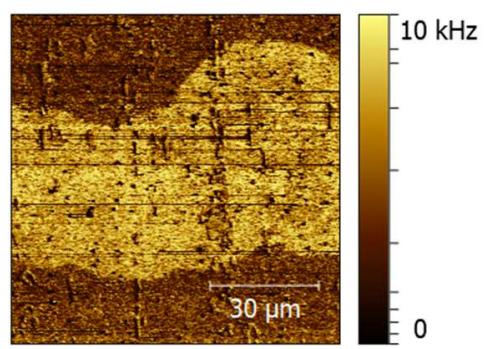

Fig. 5. Highlight of the precipitates

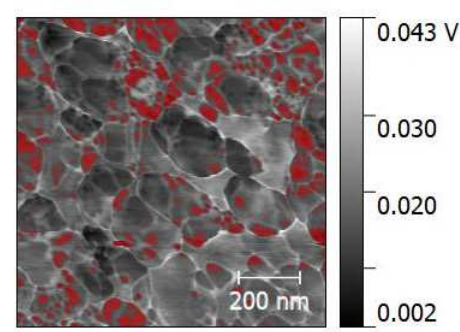

Nanoindentation analysis is focused on main microstructure parts revealed through the microstructure study by AFM and optic microscopy. Selected surface area was scanned by SPM by using nanoindentation probe first. In the next step, nanoindentation process was performed on selected location in the SPM image. There is an SMP image of a big $\mathrm{Mg}_{2} \mathrm{Si}$ particle in Fig. 7a and little particles of 
$\mathrm{Al}_{\mathrm{x}}(\mathrm{Fe}, \mathrm{Mn})_{\mathrm{y}} \mathrm{Si}_{\mathrm{z}}$ type phase in Fig. $7 \mathrm{~b}$. Nanoindentation positions are also depicted in both figures. The measured values of nanoindentation hardness $H$ and the reduced elastic modulus $E_{r}$ for all evaluated positions and their description are in Table 3. Some measured positions were placed in a solid solution $\alpha$ (Al-Si). A particle of $\mathrm{Mg}_{2} \mathrm{Si}$ has relatively higher hardness in comparison to $\alpha$ matrix, but its Young modulus is lower. The measured $\mathrm{Alx}(\mathrm{Fe}, \mathrm{Mn}) \mathrm{ySiz}$ type particles have higher (but comparable) values of both hardness and modulus than the $\alpha$ matrix. Similarity between mechanical properties of these two structure constituents indicate some coherency between their crystallic structures.

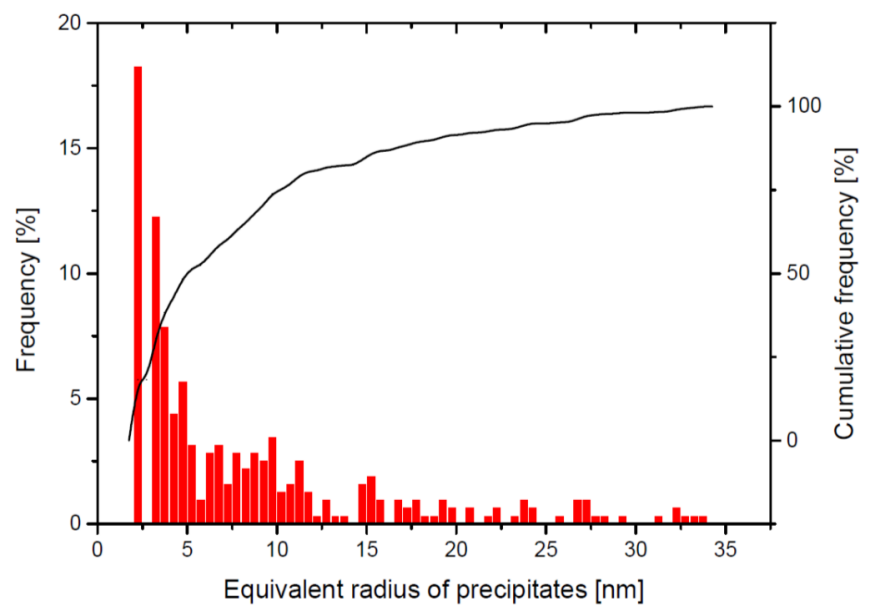

Fig. 6. Frequency and cumulative frequency of precipitates in a $1 \mathrm{x} 1 \mu \mathrm{m}^{2}$ surafce

Table 2. Statistical evaluation of the precipitates size by equivalent radius

\begin{tabular}{|c|c|c|}
\hline Parameter & Mean & Median \\
\hline Radius of equivalent circle & $8.255 \mathrm{~nm}$ & $5.420 \mathrm{~nm}$ \\
\hline
\end{tabular}

a)

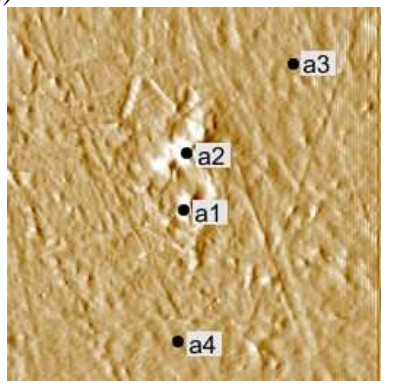

b)

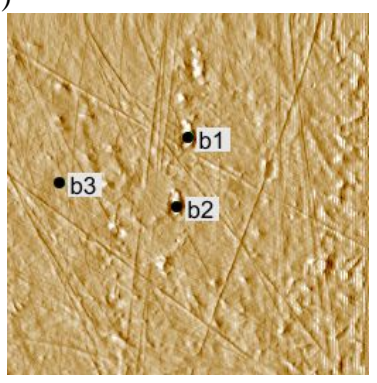

Fig. 7. SPM image of $\mathrm{Mg}_{2} \mathrm{Si}$ (a) and $\mathrm{Al}_{\mathrm{x}}\left(\mathrm{Fe}, \mathrm{Mn}_{\mathrm{y}} \mathrm{Si}_{\mathrm{z}}\right.$ (b) type particles with nanoindentation positions (both $10 \times 10 \mu \mathrm{m}$ ) gradient 
Table 3. Nanoindentation hardness and reduced modulus particular structure constituents

\begin{tabular}{|c|c|c|c|}
\hline $\begin{array}{c}\text { Nanoindentation hardness } \\
H[\mathrm{GPa}]\end{array}$ & $\begin{array}{c}\text { Reduced } \\
\text { modulus } E_{\mathrm{r}} \\
{[\mathrm{GPa}]}\end{array}$ & Nanoindentation position & \multirow{2}{*}{ Phase } \\
\hline 2.89 & 68.83 & $\mathrm{a} 1$ & \multirow{2}{*}{$\mathrm{Mg}_{2} \mathrm{Si}$ particle } \\
\hline 3.16 & 75.40 & $\mathrm{a} 2$ & \multirow{2}{*}{$\alpha$} \\
\hline 1.50 & 78.18 & $\mathrm{a} 3$ & \multirow{2}{*}{$\begin{array}{c}\mathrm{Al}_{\mathrm{x}}(\mathrm{Fe}, \mathrm{Mn})_{\mathrm{y}} \mathrm{Si}_{\mathrm{z}} \text { type } \\
\text { particles }\end{array}$} \\
\hline 1.73 & 84.78 & $\mathrm{a} 4$ & $\alpha$ \\
\hline 1.88 & 86.46 & $\mathrm{~b} 1$ & $\mathrm{~b} 2$ \\
\hline 1.94 & 77.99 & $\mathrm{~b} 3$ & \\
\hline
\end{tabular}

\section{Conclusions}

As it is proven in the article, AFM microscopy could certainly replace TEM microscopy in some cases of material structure investigation, for instance identification of present phases and their morphology and distribution. Moreover, quasistatic nanoindentation allows to measure local mechanical properties of these material structure constituents. Aluminium alloy of EN AW 6082-T651 is investigated in the paper. AFM microscopy revealed precipitates with mean radius of $8 \mathrm{~nm}$. Evaluation of precipitates distribution and their size could be concluded that with the increasing size of precipitates, their frequency of occurrence decreases. The applied nanoindentation device uses SPM to visualise measured area where the nanoindentation tip oscillates and taps over the area. The principle is principally similar to AFM but SPM does not reach resolution and sensitiveness of AFM. Therefore, more detailed phases like small precipitates are not visible observing the alloy by using built-in SPM microscopy. However, other structure constituens identificated by AFM were reliably measured by nanoindentaiton and their nanoindentation hardness and reduced modulus were evlauated.

\section{References}

[1] Kuijpers N.C.W., Tirel J., Hanlon D.N., Zwaag S.: Quantification of the evolution of the 3D intermetallic structure in a $6005 \mathrm{~A}$ aluminium alloy during a homogenisation treatment, Mater. Charact., 48 (2002) 379-392.

[2] Mrowka-Nowotnik G., Sieniawski J., Wierzbinska M.: Analysis of intermetallic particles in AlSi1MgMn aluminium alloy, J. Achiev. Mater. Manuf. Eng., 20 (2007) 155-158.

[3] Vissers R., Van Huis A., Jansen J., Zandberger H.W., Marioara C.D., Andersen S.J.: The crystal structure of the 0 phase in Al-Mg-Si alloys, Acta Materialia, 55 (2007) 3815-3823.

[4] Mariora C.D., Nordmark H., Andersen S.J., Holmestand R.: Post- $\beta$ " phases and their influence on microstructure and hardness in 6xxx Al-Mg-Si alloys, J. Mater. Sci., 41 (2006) 471-478. 
[5] Katgerman L., Eskin D.: Hardening, Annealing and Aging, Handbook of Aluminum, Physical Metallurgy and Processes, CRS Taylor and Francis, London, New York 2003, pp. 259-303.

[6] Miao W.F., Laughlin D.E.: Effects of $\mathrm{Cu}$ content and preaging on precipitation characteristics in aluminum alloy 6022, Metall. Mater. Trans. A, 31 (2000) 361-371.

[7] Matsuda K., Teguri D., Uetani Y., Sato Y., Ikeno S.: Microstructure and nanosegregation of $\mathrm{Cu}$ in Al-Mg-Si-Cu alloys, Scripta Materiala, 47 (2002) 833-837.

[8] Jin M., Li J., Shao G.: Study of $\mathrm{Cu}$ addition on precipitation behaviors and mechanical properties in AA6082 Al-Mg-Si alloy, Mater. Sci. Forum, 546 (2007) 825-828.

[9] Fischer-Cripps A.C.: Nanoindentation, Springer, 2011.

[10] Oliver W.C., Pharr G.M.: An improved technique for determining hardness and elastic modulus using load and displacement sensing indentation experiments. J Mater. Res., 7 (1992) 1564-1583.

[11] Hardiman M.: Nanoindentation of fibrous composite microstructures: experimentation and finite element investigation, Internet Article, Dublin City University, 2017.

[12] Mahani Y.N., Tajvidi M.: Viscoelastic mapping of spruce-polyurethane bond line area using AM-FM atomic force microscopy, Int. J. Adhesion Adhesives, 79 (2017) 59-66.

\section{ANALIZA AFM I NANOINDENTACJA WYBRANYCH STOPÓW ALUMINIUM}

\section{Streszczenie}

W artykule opisano strukturę stopu aluminium AW 6082. Mikroskopia sił atomowych (AFM) służy do identyfikacji obecnych faz i ich morfologii. AFM umożliwił obserwację nawet wtrąceń, ich wielkości i rozmieszczenia. W następnym etapie niektóre składniki struktury opisane przez AFM zostały ocenione w procesie nanoindentacji w celu określenia ich lokalnych właściwości mechanicznych, takich jak nanotwardość i zredukowany moduł.

Słowa kluczowe: stop aluminium, składnik struktury, nanoindentacja, wtrącenia

DOI: $10.7862 / \mathrm{rm} .2018 .11$

Przestano do redakcji: 24.04 .2018

Przyjęto do druku: 14.05.2018 